\title{
Suberoylanilide hydroxamic acid-induced HeLa cell death is closely correlated with oxidative stress and thioredoxin 1 levels
}

\author{
BO RA YOU and WOO HYUN PARK
}

\begin{abstract}
Department of Physiology, Medical School, Research Institute for Endocrine Sciences, Chonbuk National University, Jeonju 561-180, Republic of Korea
\end{abstract}

Received December 10, 2013; Accepted February 6, 2014

DOI: $10.3892 /$ ijo.2014.2337

\begin{abstract}
Suberoylanilide hydroxamic acid (SAHA) is a histone deacetylase (HDAC) inhibitor which has anticancer effects. We evaluated the growth inhibitory effects of SAHA on HeLa cervical cancer cells in relation to reactive oxygen species (ROS) levels. SAHA inhibited the growth of HeLa cells with an $\mathrm{IC}_{50}$ of approximately $10 \mu \mathrm{M}$ at $24 \mathrm{~h}$, and induced apoptosis which was accompanied by the cleavage of PARP, caspase-3 activation and loss of mitochondrial membrane potential (MMP; $\Delta \Psi_{\mathrm{m}}$ ). All the tested caspase inhibitors prevented HeLa cell death induced by SAHA whereas TNF- $\alpha$ intensified apoptotic cell death in SAHA-treated HeLa cells. With respect to ROS and glutathione (GSH) levels, SAHA increased ROS levels, especially mitochondrial $\mathrm{O}_{2}{ }^{-}$in $\mathrm{HeLa}$ cells and also induced GSH depletion. Caspase inhibitors reduced the levels of ROS and GSH depletion in SAHAtreated HeLa cells whereas TNF- $\alpha$ enhanced the levels in
\end{abstract}

Correspondence to: Professor Woo Hyun Park, Department of Physiology, Medical School, Chonbuk National University, Jeonju 561-180, Republic of Korea

E-mail: parkwh71@chonbuk.ac.kr

Abbreviations: SAHA, suberoylanilide hydroxamic acid; HDAC, histone deacetylase; ROS, reactive oxygen species; MMP $\left(\Delta \Psi_{\mathrm{m}}\right)$, mitochondrial membrane potential; FBS, fetal bovine serum; MTT, 3-(4,5-dimethylthiazol-2-yl)-2,5-diphenyltetrazolium bromide; PI, propidium iodide; FITC, fluorescein isothiocyanate; Z-VAD-FMK, benzyloxycarbonyl-Val-Ala-Asp-fluoromethylketone; Z-DEVD-FMK, benzyloxycarbonyl-Asp-Glu-Val-Asp-fluoromethylketone; Z-IETD-FMK, benzyloxycarbonyl-Ile-Glu-Thr-Asp-fluoromethylketone; Z-LEHD-FMK, benzyloxycarbonyl-Leu-Glu-His-Asp-fluoromethylketone; TNF- $\alpha$, tumor necrosis factor- $\alpha$; TRAIL, TNF-related apoptosis-inducing ligand; FasL, Fas ligand; LDH, lactate dehydrogenase; NAC, N-acetyl cysteine; $\mathrm{H}_{2}$ DCFDA, 2',7'-dichlorodihydrofluorescein diacetate; DHE, dihydroethidium; GSH, glutathione; CMFDA, 5-chloromethylfluorescein diacetate; Trx, thioredoxin; TrxR, thioredoxin reductase; $\mathrm{Cu} / \mathrm{Zn} \mathrm{SOD}$, copper zinc superoxide dismutase; MnSOD, manganese superoxide dismutase

Key words: suberoylanilide hydroxamic acid, reactive oxygen species, apoptosis, thioredoxin, HeLa cells these cells. The well-known antioxidant $\mathrm{N}$-acetyl cysteine (NAC) attenuated cell death and an increase in ROS levels was caused by SAHA. Moreover, SAHA decreased the levels of thioredoxin 1 ( $\operatorname{Tr} x 1)$ in HeLa cells. While the downregulation of Trx1 enhanced cell death and ROS levels in SAHA-treated HeLa cells, the overexpression of Trx1 attenuated the levels in these cells. In conclusion, SAHA inhibited the growth of HeLa cell via caspase-dependent apoptosis, which was influenced by the mitochondrial $\mathrm{O}_{2}{ }^{--}$and $\operatorname{Trx} 1$ levels.

\section{Introduction}

The major reactive oxygen species (ROS) are hydroxyl radical $\left({ }^{\circ} \mathrm{OH}\right)$, superoxide anion $\left(\mathrm{O}_{2}{ }^{\circ}\right)$ and hydrogen peroxide $\left(\mathrm{H}_{2} \mathrm{O}_{2}\right)$, which are involved in a variety of cellular events such as transcription factor activation and cell proliferation (1). ROS can also induce damage in cells and tissues via the oxidation of DNA, lipid and protein (2). Therefore, cells and tissues have various antioxidants and systems to control the excessive ROS level. Superoxide dismutase (SOD), which metabolizes superoxide anion $\left(\mathrm{O}_{2}{ }^{-}\right)$to hydrogen peroxide $\left(\mathrm{H}_{2} \mathrm{O}_{2}\right)$, is expressed as extracellular (ecSOD), intracellular $(\mathrm{Cu} / \mathrm{ZnSOD})$ and mitochondrial (MnSOD) isoforms (3). Glutathione $(\mathrm{GSH})$ is a dominant non-protein antioxidant in cells and supplies electrons for glutathione peroxidase to detoxify $\mathrm{H}_{2} \mathrm{O}_{2}$ to $\mathrm{O}_{2}$ and $\mathrm{H}_{2} \mathrm{O}$ (4). GSH is important for cell cycle progression and apoptosis and it is also known to protect cells from toxic metabolites and oxidative stress $(5,6)$. Thioredoxin ( $\operatorname{Trx}$ ) as a small protein contains cysteine residues (Cys 32 and Cys 35) in the active site and the residues exist as either a dithiol in the reduced form and a disulfide in the oxidized form (7). When Trx is oxidized, it is reduced back to dithiol by nicotinamide adenine dinucleotide phosphate (NADPH)-dependent Trx reductase (TrxR) (7). There are two isoforms of Trx; cytoplasmic (Trx1) and mitochondrial ( $\operatorname{Tr} x 2)(8)$. Especially, Trx1 is overexpressed in many cancer cells including colorectal and breast cancer $(9,10)$ and has been reported as responsible for cellular resistance to anticancer drugs (11).

Histone deacetylase (HDAC) is a class of enzyme that removes acetyl groups from lysine amino acid on histones, leading to the suppression of transcription (12). Deregulation of HDAC has been observed in malignant tissues, resulting 
in the inhibition of tumor suppressor genes, thereby allowing the expression of the malignant phenotypes (13). In addition, previous studies have demonstrated that HDAC activity is upregulated in many human cancers and suggested that the ways to inhibit HDAC activity can be a novel strategy in cancer therapeutics $(14,15)$. Suberoylanilide hydroxamic acid (SAHA) is a potent HDAC inhibitor, that has been used for the treatment of cutaneous T-cell lymphoma (16). Accumulating evidence indicates that SAHA has effects on many biological functions such as cell cycle arrest, apoptosis, invasion in cancer cells $(17,18)$. Furthermore, SAHA appears to induce cell death via generating ROS and to downregulate Trx1 via increasing thioredoxin-interacting protein (TXNIP) $(19,20)$.

Cervical cancer is a major cause of death in women worldwide and its occurrence results from both genetic and epigenetic events. Epigenetic alterations such as global DNA hypomethylation, hypermethylation of tumor suppressor genes and histone modifications occur during the carcinogenesis of cervical cancer (21). Overexpression of HDAC2 is observed in cervical cancer (22). Furthermore, the upregulation of $\operatorname{Trx}$ is found in invasive cervical carcinomas (23). It has been reported that SAHA has anticancer effects on liver, breast, ovarian and cervical cancer cells in vitro and in vivo $(17,20,24)$. However, little is known about the anticancer effect of SAHA on cervical cancer cells in view of ROS and GSH levels as well as in relation to antioxidant proteins, especially Trx1. Therefore, in the present study we investigated the effects of SAHA on cell growth and cell death in human cervical HeLa cells with respect to the levels of ROS, GSH and Trx1.

\section{Materials and methods}

Cell culture. Human cervix adenocarcinoma HeLa cells were obtained from the American Type Culture Collection (ATCC, Manassas, VA, USA) and maintained in a humidified incubator containing $5 \% \mathrm{CO}_{2}$ at $37^{\circ} \mathrm{C}$. The HeLa cells were cultured in RPMI-1640 (Sigma-Aldrich, St. Louis, MO, USA) supplemented with $10 \%$ fetal bovine serum (FBS; SigmaAldrich) and 1\% penicillin-streptomycin (Gibco BRL, Grand Island, NY, USA). The cells were routinely grown in 100-mm plastic tissue culture dishes (Nunc, Roskilde, Denmark) and harvested with a solution of trypsin-EDTA while in a logarithmic phase of growth.

Reagents. SAHA was purchased from Cayman Chemical Co. (Ann Arbor, MI, USA) and was dissolved in dimethyl sulfoxide (DMSO; Sigma-Aldrich Chemical Co.) at $10 \mathrm{mM}$ as a stock solution. The pan-caspase inhibitor (Z-VAD-FMK; benzyloxycarbonyl-Val-Ala-Asp-fluoromethylketone), caspase-3 inhibitor (Z-DEVD-FMK; benzyloxycarbonyl-Asp-Glu-ValAsp-fluoromethylketone), caspase-8 inhibitor (Z-IETD-FMK; benzyloxycarbonyl-Ile-Glu-Thr-Asp-fluoromethylketone) and caspase-9 inhibitor (Z-LEHD-FMK; benzyloxycarbonyl-LeuGlu-His-Asp-fluoromethylketone) were obtained from R\&D Systems, Inc. (Minneapolis, MN, USA) and were dissolved in DMSO at $10 \mathrm{mM}$ to serve as stock solutions. TNF- $\alpha$, TRAIL and FasL were also obtained from R\&D Systems, Inc. and were dissolved in water at $10 \mathrm{mg} / \mathrm{ml}$ as a stock solution. NAC obtained from Sigma-Aldrich Chemical Co. was dissolved in buffer [20 mM HEPES (pH 7.0)] at $100 \mathrm{mM}$ as a stock solu- tion. Cells were pretreated with $15 \mu \mathrm{M}$ caspase inhibitors or $2 \mathrm{mM}$ NAC for $1 \mathrm{~h}$ prior to SAHA treatment. DMSO (0.01\%) was used as a control vehicle and it did not affect cell growth and death.

Growth inhibition assay. The effect of SAHA on cell growth was determined by measuring 3-(4,5-dimethylthiazol-2-yl)2,5-diphenyltetrazolium bromide (MTT; Sigma-Aldrich) absorbance in living cells as described previously (25). In brief, $5 \times 10^{3}$ cells were seeded in 96-well microtiter plates (Nunc) for MTT assays. After exposure to the designated doses of SAHA with or without $15 \mu \mathrm{M}$ each caspase inhibitor, $2 \mathrm{mM}$ NAC, Trx1 siRNA or adTrx1 for the indicated times, MTT solution [20 $\mu \mathrm{l}: 2 \mathrm{mg} / \mathrm{ml}$ in phosphate-buffered saline (PBS)] was added to each well of the 96 -well plates. The plates were additionally incubated for $3 \mathrm{~h}$ at $37^{\circ} \mathrm{C}$. Medium was withdrawn from the plates by pipetting and $200 \mu \mathrm{l}$ DMSO was added to each well to solubilize the formazan crystals. The optical density was measured at $570 \mathrm{~nm}$ using a microplate reader $\left(\right.$ Synergy ${ }^{\mathrm{TM}} 2$, BioTek Instruments Inc., Winooski, VT, USA).

Cell cycle and sub-G1 cell analysis. Cell cycle and sub-G1 cell analysis were determined by propidium iodide (PI, Ex/ Em=488/617 nm; Sigma-Aldrich) staining as described previously (26). In brief, $1 \times 10^{6}$ cells in a $60-\mathrm{mm}$ culture dish (Nunc) were incubated with the designated doses of SAHA with or without $15 \mu \mathrm{M}$ caspase inhibitors, $2 \mathrm{mM}$ NAC, Trx1 siRNA or adTrx 1 for $24 \mathrm{~h}$. Cells were washed again with PBS, then incubated with PI $(10 \mu \mathrm{g} / \mathrm{ml})$ with simultaneous RNase treatment at $37^{\circ} \mathrm{C}$ for $30 \mathrm{~min}$. Cellular DNA content was measured using a FACStar flow cytometer (Becton-Dickinson, Franklin Lakes, NJ, USA) and analyzed by using lysis II and Cellfit software (Becton-Dickinson).

Annexin V-FITC/PI staining for cell death detection. Apoptotic cell death was determined by staining cells with Annexin V-fluorescein isothiocyanate (FITC, Invitrogen Life Technologies, Camarillo, CA, USA; Ex/Em=488/519 nm) as described previously (26). In brief, $1 \times 10^{6}$ cells in a $60-\mathrm{mm}$ culture dish (Nunc) were incubated with the designated doses of SAHA with or without $15 \mu \mathrm{M}$ caspase inhibitors, $10 \mathrm{ng} / \mathrm{ml}$ TNF family members, 2 mM NAC, Trx 1 siRNA or adTrx 1 for $24 \mathrm{~h}$. Cells were washed twice with cold PBS and then resuspended in $500 \mu \mathrm{l}$ of binding buffer $(10 \mathrm{mM}$ HEPES/NaOH $\left.\mathrm{pH} 7.4,140 \mathrm{mM} \mathrm{NaCl}, 2.5 \mathrm{mM} \mathrm{CaCl}_{2}\right)$ at a concentration of $1 \times 10^{6}$ cells $/ \mathrm{ml}$. Annexin V-FITC $(5 \mu \mathrm{l})$ and PI $(1 \mu \mathrm{g} / \mathrm{ml})$ were then added and the cells were analyzed with a FACStar flow cytometer.

Quantification of caspase-3 activity. The activity of caspase-3 was assessed using the caspase- 3 colorimetric assay kit (R\&D Systems, Inc.) as previously described (27). In brief, $1 \times 10^{6}$ cells in a $60-\mathrm{mm}$ culture dishes (Nunc) were incubated with $10 \mu \mathrm{M}$ SAHA for $24 \mathrm{~h}$. The cells were then washed in PBS and suspended in five volumes of lysis buffer provided with the kit. Protein concentrations were determined using the Bradford method. Supernatants containing $50 \mu \mathrm{g}$ total protein were used to determine caspase- 3 activity. The supernatants were added to each well in 96-well microtiter plates (Nunc) with DEVD-pNA as a caspase-3 substrate and the plates were 
incubated at $37^{\circ} \mathrm{C}$ for $1 \mathrm{~h}$. The optical density of each well was measured at $405 \mathrm{~nm}$ using a microplate reader (Synergy 2, BioTek Instruments Inc.). Caspase-3 activity was expressed in arbitrary absorbance units.

Western blot analysis. The expression of proteins was evaluated using western blot analysis as previously described (28). In brief, $1 \times 10^{6}$ cells in a $60-\mathrm{mm}$ culture dish (Nunc) were incubated with the designated doses of SAHA for $24 \mathrm{~h}$. The cells were then washed in PBS and suspended in five volumes of lysis buffer (20 mM HEPES, pH 7.9, 20\% glycerol, $200 \mathrm{mM} \mathrm{KCl,}$ $0.5 \mathrm{mMEDTA}, 0.5 \% \mathrm{NP} 40,0.5 \mathrm{mM}$ DTT, $1 \%$ protease inhibitor cocktail). Supernatant protein concentrations were determined using the Bradford method. Supernatant samples containing $30 \mu \mathrm{g}$ total protein were resolved by 7.5 or $12.5 \%$ SDS-PAGE gels depending on the sizes of target proteins, transferred to Immobilon-P PVDF membranes (Millipore, Billerica, MA, USA) by electroblotting, and then probed with anti-ac-H3, anti-PARP, anti-c-PARP, anti-Bcl-2, anti-Bax (Cell Signaling Technology Inc., Danvers, MA, USA), anti-Trx1, anti-Trx2, anti-TrxR1, anti-Cu/ZnSOD, anti-MnSOD and anti- $\beta$-actin antibodies (Santa Cruz Biotechnology, Santa Cruz, CA, USA). Membranes were incubated with horseradish peroxidaseconjugated secondary antibodies. Blots were developed using an ECL kit (Amersham, Arlington Heights, IL, USA).

Measurement of MMP $\left(\Delta \Psi_{m}\right)$. The MMP $\left(\Delta \Psi_{\mathrm{m}}\right)$ levels were measured by a rhodamine 123 fluorescent dye (Sigma-Aldrich; $\mathrm{Ex} / \mathrm{Em}=485 / 535 \mathrm{~nm}$ ) as described previously $(26,29)$. In brief, $1 \times 10^{6}$ cells in a $60-\mathrm{mm}$ culture dish (Nunc) were incubated with the designated doses of SAHA for $24 \mathrm{~h}$. Cells were washed twice with PBS and incubated with rhodamine 123 $(0.1 \mu \mathrm{g} / \mathrm{ml})$ at $37^{\circ} \mathrm{C}$ for $30 \mathrm{~min}$. Rhodamine 123 staining intensity was determined by a FACStar flow cytometer. The cells that were rhodamine 123-negative were indicated to have lost $\operatorname{MMP}\left(\Delta \Psi_{\mathrm{m}}\right)$. MMP $\left(\Delta \Psi_{\mathrm{m}}\right)$ levels in cells except MMP $\left(\Delta \Psi_{\mathrm{m}}\right)$ loss are expressed as mean fluorescence intensity (MFI), which was calculated by CellQuest software.

Detection of intracellular ROS levels. Intracellular ROS such as $\mathrm{H}_{2} \mathrm{O}_{2},{ }^{\circ} \mathrm{OH}$, and $\mathrm{ONOO}^{\bullet}$ were detected by means of an oxidation-sensitive fluorescent probe dye, 2',7'-dichlorodihydrofluorescein diacetate $\left(\mathrm{H}_{2} \mathrm{DCFDA}\right.$, Invitrogen Molecular Probes, OR, USA; Ex/Em=495/529nm) (26). Mitochondrial $\mathrm{O}_{2}{ }^{--}$level was specifically detected using a MitoSox ${ }^{\mathrm{TM}}$ Red mitochondrial $\mathrm{O}_{2}{ }^{--}$indicator (Invitrogen Molecular Probes; $\mathrm{Ex} / \mathrm{Em}=510 / 580 \mathrm{~nm}$ ). In brief, $1 \times 10^{6}$ cells in $60-\mathrm{mm}$ culture dishes (Nunc) were incubated the designated doses of SAHA with or without $15 \mu \mathrm{M}$ caspase inhibitors, $10 \mathrm{ng} / \mathrm{ml} \mathrm{TNF}$ family members, 2 mM NAC, Trx1 siRNA or adTrx 1 for $24 \mathrm{~h}$. Cells were then washed in PBS and incubated with $20 \mu \mathrm{M}$ $\mathrm{H}_{2}$ DCFDA or $5 \mu \mathrm{M}$ MitoSox Red at $37^{\circ} \mathrm{C}$ for $30 \mathrm{~min}$. DCF and MitoSox Red fluorescence were detected using a FACStar flow cytometer. ROS and mitochondrial $\mathrm{O}_{2}^{-{ }^{-}}$levels were expressed as MFI, which was calculated by CellQuest software (BectonDickinson).

Detection of intracellular glutathione (GSH). Cellular GSH levels were analyzed using a 5-chloromethylfluorescein diacetate dye (CMFDA, Ex/Em=522/595 nm; Invitrogen
Life Technologies) as previously described (30). In brief, $1 \times 10^{6}$ cells were incubated in a $60-\mathrm{mm}$ culture dishes (Nunc) with the designated doses of SAHA with or without $15 \mu \mathrm{M}$ caspase inhibitors, 2 mM NAC, Trx1 siRNA or adTrx1 for $24 \mathrm{~h}$. Cells were then washed with PBS and incubated with $5 \mu \mathrm{M} \mathrm{CMFDA}$ at $37^{\circ} \mathrm{C}$ for $30 \mathrm{~min}$. CMF fluorescence intensity was determined using a FACStar flow cytometer. Negative $\mathrm{CMF}$ staining (GSH-depletion) of cells is expressed as the percentage of (-) CMF cells.

Lactate dehydrogenase ( $\mathrm{LDH}$ ) activity for the detection of necrosis. Necrosis in cells treated with SAHA and/or TNF family members was evaluated by LDH kit (Sigma-Aldrich Chemical Co.). In brief, $1 \times 10^{6}$ cells in $60-\mathrm{mm}$ culture dish (Nunc) were incubated with the indicated doses of SAHA and/ or TNF family members for $24 \mathrm{~h}$. After treatment, the culture media were collected and centrifuged for $5 \mathrm{~min}$ at $1,500 \mathrm{rpm}$. The supernatant $(50 \mu \mathrm{l})$ was added to a fresh 96 -well plate along with LDH assay reagent and then incubated at room temperature for $30 \mathrm{~min}$. The absorbance values were measured at $490 \mathrm{~nm}$ using a microplate reader. LDH release was expressed as the percentage of extracellular LDH activity compared with the control cells.

Transfection of cells with Trx 1 siRNA. Gene silencing of TrxR1 was performed as previously described $(31,32)$. A non-specific control (CTR) siRNA duplex [5'-CCUACGCCACCAAUUUC GU(dTdT)-3'] and Trx1 siRNA duplex [5'-GCAUGCCAACAU UCCAGUU(dTdT)-3'] were purchased from the Bioneer Corp.

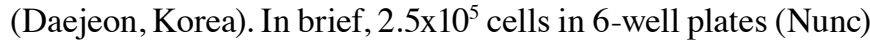
were incubated in RPMI-1640 supplemented with 10\% FBS. After $24 \mathrm{~h}$, the cells ( $\sim 30-40 \%$ confluence) in each well were transfected with the CTR or Trx1 siRNA duplex [80 pmol in Opti-MEM (Gibco BRL)] using Lipofectamine 2000, according to the manufacturer's instructions (Invitrogen, Brandford, CT, USA). One day later, the cells were treated with or without $10 \mu \mathrm{M}$ SAHA for additional $24 \mathrm{~h}$. The transfected cells were used for western blot analysis, MTT and cell death assays, and ROS and GSH level measurements.

Infection of cells with adTrx1. Overexpression of Trx1 was performed using an adenoviral gene transfer. adLacZ and adTrx1 were obtained from Dr J. Sadoshima, New Jersey Medical School, Newark, USA. In brief, $5 \times 10^{5}$ cells in 6 -well plates (Nunc) were incubated in RPMI-1640 supplemented with $10 \%$ FBS. The cells ( 50-60\% confluence) in each well were infected with the same titer adLacZ or adTrxR1, as determined by plague assay. One day later, the cells were treated with or without $10 \mu \mathrm{M}$ SAHA for additional $24 \mathrm{~h}$. The infected cells were collected and used for western blot analysis, MTT and cell death assays, and ROS and GSH level measurements.

Statistical analysis. The results represent the mean of at least three independent experiments (mean $\pm \mathrm{SD}$ ). Data were analyzed using Instat software (GraphPad Prism4, San Diego, CA, USA). The Student's t-test or one-way analysis of variance (ANOVA) with post hoc analysis using Tukey's multiple comparison test was used for parametric data. The statistical significance was defined as $\mathrm{p}<0.05$. 
A

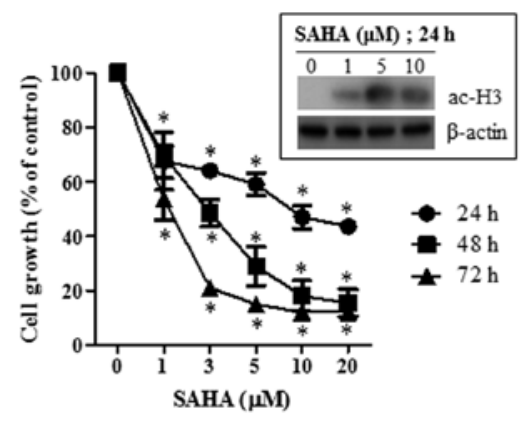

D

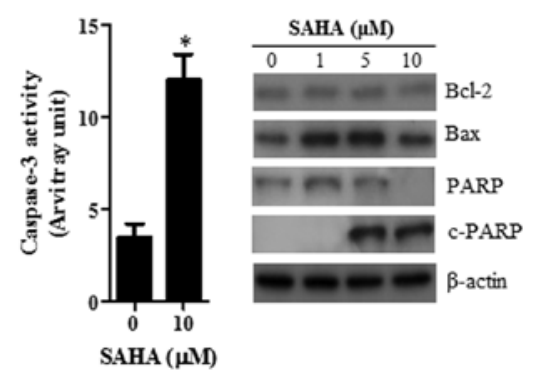

B

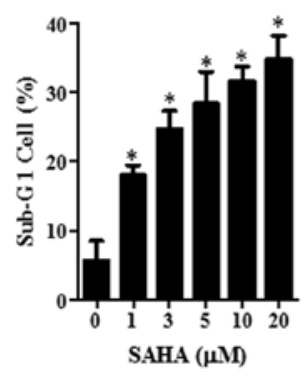

$\mathbf{E}$

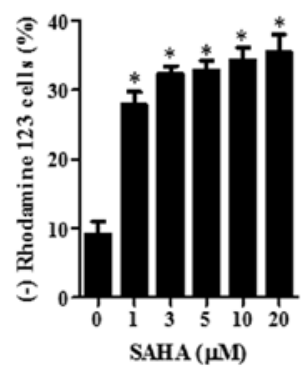

C

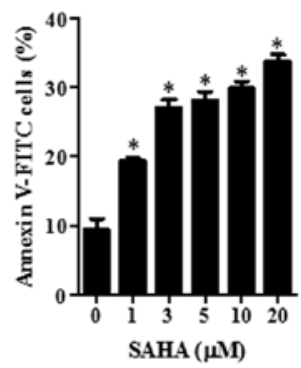

$\mathbf{F}$

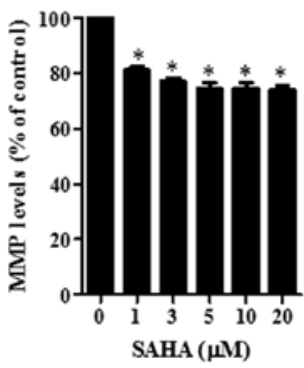

Figure 1. Effects of SAHA on cell growth and death in HeLa cells. Exponentially growing cells were treated with the designated concentrations of SAHA for the indicated times. (A) Graph for cellular growth changes in HeLa cells at $24 \mathrm{~h}$ as assessed by MTT assays. The inside figure indicates changes in acetylatedhistone 3 as assessed by western blotting described in Materials and methods. (B and C) Graphs for the percentages of sub-G1 cells and Annexin V-positive cells at $24 \mathrm{~h}$, respectively, as measured by FACStar flow cytometer. (D) Graph for the activity of caspase-3 at $24 \mathrm{~h}$ in SAHA-treated cells. Western blot analysis result shows the levels of PARP, c-PARP, Bcl-2, Bax and $\beta$-actin. (E and F) Graphs for the percentages of rhodamine 123-negative [MMP $\left(\Delta \Psi_{\mathrm{m}}\right)$ loss] cells and $\operatorname{MMP}\left(\Delta \Psi_{\mathrm{m}}\right)$ levels in HeLa cells at $24 \mathrm{~h} .{ }^{*} \mathrm{p}<0.05$ compared with the control group.

\section{Results}

Effects of SAHA on cell growth, cell death and $M M P\left(\Delta \Psi_{m}\right)$ in HeLa cells. First, the effect of SAHA on the growth inhibition of HeLa cells was examined using MTT assays. After exposure to SAHA for 24, 48 and $72 \mathrm{~h}$, the growth of HeLa cells was dose- and time-dependently decreased with an $\mathrm{IC}_{50}$ of $\sim 10,3$ and $1 \mu \mathrm{M}$ at 24,48 and $72 \mathrm{~h}$, respectively (Fig. 1A). In addition, SAHA increased the level of acetylated H3 in HeLa cells at $24 \mathrm{~h}$, implying that SAHA worked as a HADC inhibitor in these cells (Fig. 1A).

As shown in Fig. 1B, SAHA increased the number of sub-G1 cells in HeLa cells in a dose-dependent manner at $24 \mathrm{~h}$. When HeLa cells were stained with Annexin V-FITC to evaluate the induction of apoptosis, the percentages of Annexin V-staining cells were dose-dependently increased in SAHA-treated HeLa cells (Fig. 1C). In addition, the activity of caspase-3 was increased in SAHA-treated HeLa cells (Fig. 1D). The examination of the expressions in apoptotic-related proteins showed that Bcl-2 and Bax proteins were downregulated and upregulated by SAHA, respectively (Fig. 1D). The intact of poly(ADP-ribose) polymerase (PARP) was also decreased and instead the cleavage form of PARP was induced by SAHA (Fig. 1D). Furthermore, SAHA increased the percentage of MMP $\left(\Delta \Psi_{\mathrm{m}}\right)$ loss cells (Fig. 1E) and reduced MMP $\left(\Delta \Psi_{\mathrm{m}}\right)$ levels in HeLa cells at $24 \mathrm{~h}$ (Fig. 1F).

Effects of SAHA on intracellular ROS and GSH levels in HeLa cells. Changes in the intracellular ROS and GSH levels
A

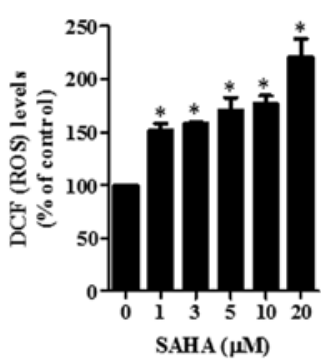

B

C

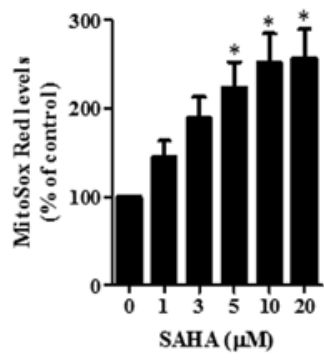

D
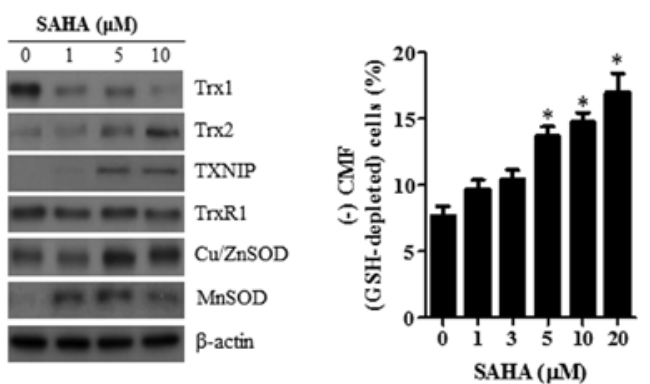

Figure 2. Effects of SAHA on the intracellular ROS and GSH levels in HeLa cells. Exponentially growing cells were treated with the designated concentration of SAHA for $24 \mathrm{~h}$. ROS and GSH levels in cells were measured with FACStar flow cytometer. (A and B) Graphs showing DCF (ROS) and MitoSox (mitochondrial $\mathrm{O}_{2}^{\circ}$ ) levels compared with those in the control cells, respectively. (C) Western blot analysis result shows the levels of $\operatorname{Trx} 1$, Trx2, TrxR1, TXNIP, Cu/ZnSOD, MnSOD and $\beta$-actin. (D) Graph for the percentage of (-) CMF (GSH-depleted) cells in HeLa cells. "p $<0.05$ compared with the control group. 
A

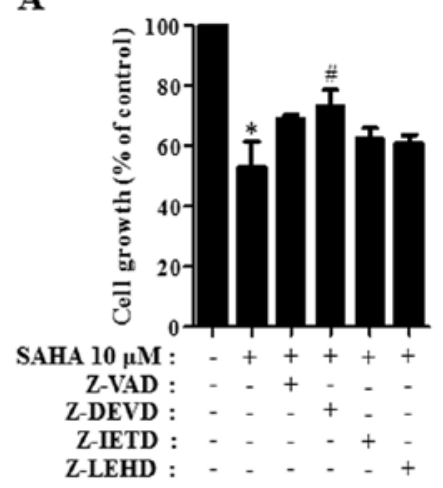

D

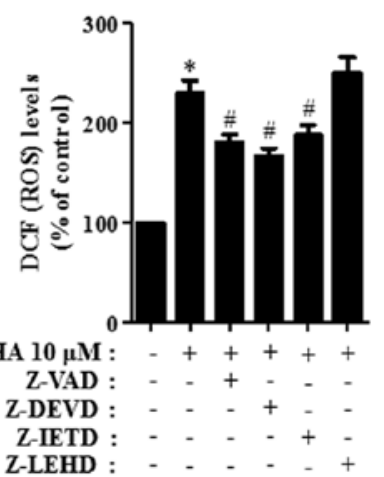

B

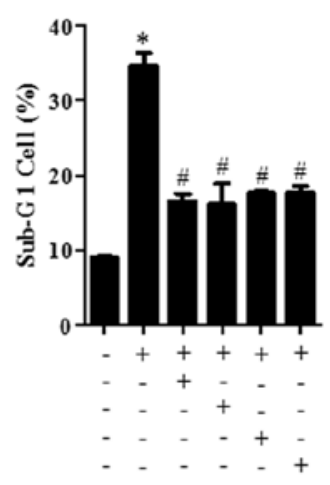

E

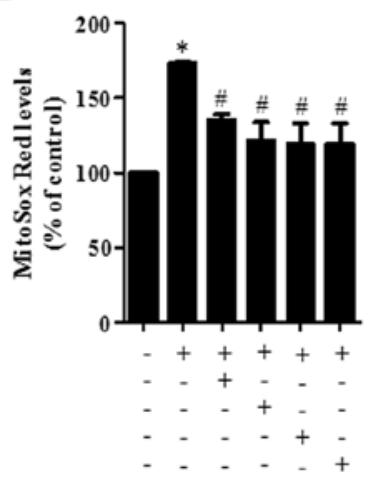

C

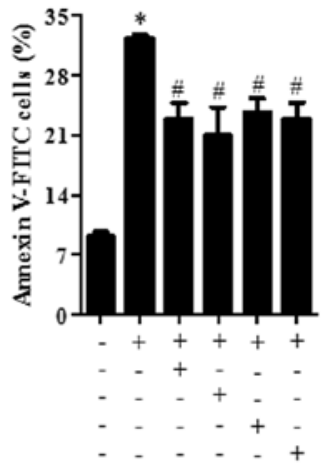

F

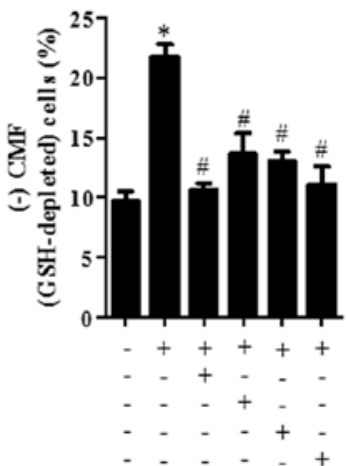

Figure 3. Effects of caspase inhibitors on cell growth, cell death, ROS and GSH levels in SAHA-treated HeLa cells. Exponentially growing cells were treated with $10 \mu \mathrm{M}$ SAHA and/or $15 \mu \mathrm{M}$ caspase inhibitors for $24 \mathrm{~h}$. (A) Cellular growth changes in HeLa cells. (B and C) The percentages of sub-G1 cells and Annexin V-positive cells, respectively. (D and E) DCF (ROS) and MitoSox (mitochondrial $\mathrm{O}_{2}^{\circ}$ ) levels compared with those in the control cells, respectively. (F) The percentage of (-) CMF (GSH-depleted) cells in HeLa cells. ${ }^{*} \mathrm{p}<0.05$ compared with the control group. ${ }^{\#} \mathrm{p}<0.05$ compared with cells treated with SAHA only.

were investigated in HeLa cells treated with SAHA. As shown in Fig. 2A, SAHA significantly increased the intracellular ROS (DCF) levels in HeLa cells at $24 \mathrm{~h}$. The level of red fluorescence derived from MitoSox, which specifically reflects mitochondrial $\mathrm{O}_{2}{ }^{-}$accumulation, was markedly increased in SAHA-treated HeLa cells in a dose-dependent manner at $24 \mathrm{~h}$ (Fig. 2B). In addition, the examination of the expressions in antioxidant-related proteins showed that the level of Trx1 was downregulated by SAHA whereas the levels of Trx2, TXNIP, $\mathrm{Cu} / \mathrm{ZnSOD}$ and MnSOD were upregulated by this agent (Fig. 2C). With respect to GSH levels as measured by a CMF fluorescence dye, SAHA significantly increased the percentages of GSH-depleted cells in HeLa cells at $24 \mathrm{~h}$ (Fig. 2D).

Effects of caspase inhibitors on cell growth, cell death, ROS and GSH levels in SAHA-treated HeLa cells. We determined which caspases were involved in the death of SAHA-treated HeLa cells. For this experiment, we chose $10 \mu \mathrm{M}$ SAHA as a suitable dose to differentiate the level of cell death in the presence or absence of each caspase inhibitor [pan-caspase inhibitor (Z-VAD), caspase-3 inhibitor (Z-DEVD), caspase-8 inhibitor (Z-IELD), or caspase-9 inhibitor (Z-LEHD)]. A concentration of $15 \mu \mathrm{M}$ each caspase inhibitor was used as an optimal dose in this study since it did not significantly affect cell death in the control HeLa cells (33). All the caspase inhibitors, especially Z-DEVD, attenuated cell growth inhibition induced by SAHA in HeLa cells at $24 \mathrm{~h}$ (Fig. 3A). Moreover, all caspase inhibitors attenuated the percentages of sub-G1 cells in SAHA-treated HeLa cells (Fig. 3B) and they prevented apoptotic cell death in these cells (Fig. 3C). Therefore, the activation of various caspases seemed to be involved in apoptotic HeLa cell death caused by SAHA.

To determine whether the levels of intracellular ROS and GSH in $10 \mu \mathrm{M}$ SAHA-treated HeLa cells were changed by treatment with each caspase inhibitor, ROS and GSH levels in HeLa cells were assessed at $24 \mathrm{~h}$. The caspase inhibitors except Z-LEHD significantly reduced ROS (DCF) levels in HeLa cells treated with SAHA (Fig. 3D). In addition, all the caspase inhibitors decreased mitochondrial $\mathrm{O}_{2}{ }^{--}$level in SAHA-treated HeLa cells (Fig. 3E). Furthermore, all the caspase inhibitors significantly prevented GSH depletion caused by SAHA (Fig. 3F).

Effects of TNF-family members on cell death, $L D H$ release, ROS and GSH levels in SAHA-treated HeLa cells. It has been reported that SAHA and TNF-family members especially, TRAIL synergistically induce apoptosis in a variety of cancer cells such as breast, liver and lymphoma cells (34-36). Therefore, we investigated whether TNF-family members affect HeLa cell death induced by SAHA. As shown in Fig. 4A, TNF- $\alpha$ among the tested TNF-family members significantly intensified the percentage of Annexin V-FITC-positive cells in $1 \mu \mathrm{M}$ SAHA-treated HeLa cells and FasL also slightly increased the percentage of those (Fig. 4A). Each TNF-family member alone 
A

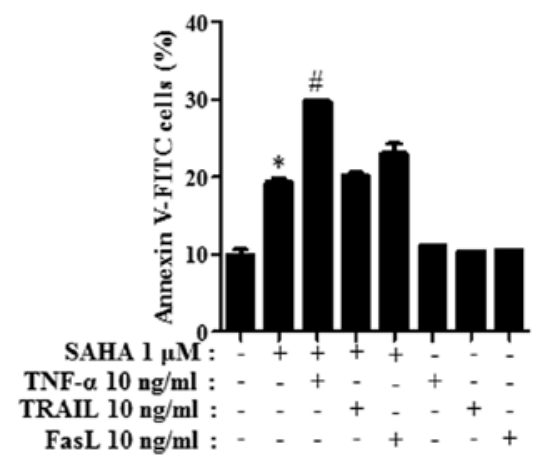

B

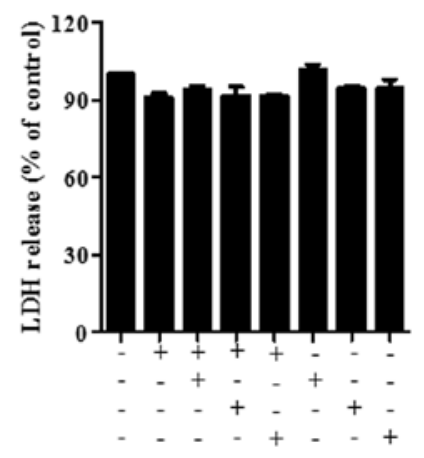

$\mathbf{E}$

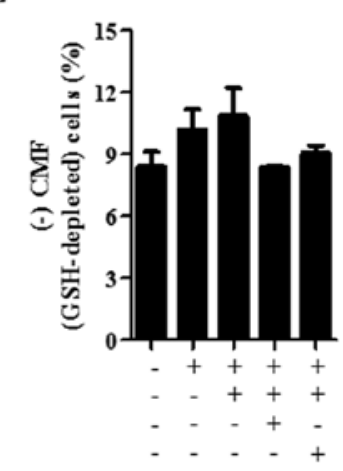

Figure 4. Effects of TNF family members on cell death, LDH release, ROS and GSH levels in SAHA-treated HeLa cells. Exponentially growing cells were treated with $1 \mu \mathrm{M}$ SAHA and/or $10 \mathrm{ng} / \mathrm{ml}$ TNF- $\alpha$, TRAIL or FasL for $24 \mathrm{~h}$. (A and C) The percentages of Annexin V-positive cells. (B) The percentage of LDH release compared with that in the control cells. (D) MitoSox (mitochondrial $\mathrm{O}_{2}^{*}$ ) levels compared with those in the control cells. (E) The percentage of (-) CMF (GSH-depleted) cells in HeLa cells. ${ }^{*}$ p $<0.05$ compared with the control group. ${ }^{*}$ p $<0.05$ compared with cells treated with SAHA only. ${ }^{\$}$ p $<0.05$ compared with cells co-treated with SAHA and TNF- $\alpha$.

did not induce apoptosis in the control HeLa cells (Fig. 4A). Since SAHA and/or TNF-family members can induce necrosis in HeLa cells, the status of necrosis was assessed using the $\mathrm{LDH}$ release. Treatment with $1 \mu \mathrm{M}$ SAHA in the presence of each TNF-family member did not lead to LDH release in HeLa cells and each TNF-family member alone did not induce LDH release either (Fig. 4B). Treatment with $10 \mu \mathrm{M}$ SAHA did not induce necrosis in HeLa cells (data not shown). When Z-IETD (caspase-8 inhibitor) and Z-LEHD (caspase-9 inhibitor) were co-incubated in HeLa cells co-treated with SAHA and TNF- $\alpha$, these inhibitors significantly prevented apoptosis caused by co-treatment with SAHA and TNF- $\alpha$ (Fig. 4C). In relation to ROS and GSH levels, TNF- $\alpha$ elevated mitochondrial $\mathrm{O}_{2}{ }^{--}$level in $1 \mu \mathrm{M}$ SAHA-treated HeLa cells and it marginally increased GSH depletion in these cells (Fig. 4D and E). Z-IETD and Z-LEHD attenuated the mitochondrial $\mathrm{O}_{2}{ }^{--}$levels in $\mathrm{HeLa}$ cells co-treated with SAHA and TNF- $\alpha$ and they prevented GSH depletion in these cells (Fig. 4D and E).

Effects of NAC on cell growth, death, ROS and GSH levels in SAHA-treated HeLa cells. Next, the effects of NAC on cell growth, cell death, ROS and GSH levels in $10 \mu \mathrm{M}$ SAHAtreated HeLa cells were assessed at $24 \mathrm{~h}$. As shown in Fig. 5A, NAC slightly recovered cell growth inhibition induced by SAHA. NAC also prevented cell death in SAHA-treated HeLa cells (Fig. 5B and C). When assessed whether NAC influences
ROS levels in SAHA-treated HeLa cells, NAC reduced ROS levels, especially mitochondrial $\mathrm{O}_{2}^{-{ }^{-}}$in these cells (Fig. 5D and E). Moreover, NAC attenuated GSH depletion in SAHAtreated HeLa cells (Fig. 5F).

Effects of Trxl siRNA and adTrxl on cell growth, cell death, ROS and GSH levels in SAHA-treated HeLa cells. Because the level of Trx1 among other antioxidant proteins was downregulated in HeLa cells by SAHA, it was hypothesized that a change in Trx1 level influences cell growth, cell death, ROS and GSH levels in SAHA-treated HeLa cells. To investigate this possibility, HeLa cells were transfected with either CTR siRNA or Trx 1 siRNA for the downregulation of $\operatorname{Trx} 1$ and they were infected with either adLacZ or adTrx 1 for the overexpression of this protein. Trx 1 level decreased greatly in HeLa cells transfected with Trx1 siRNA (Fig. 6A). As shown in Fig. 6B, treatment with Trx1 siRNA significantly enhanced cell growth inhibition in SAHA-treated HeLa cells and inhibited cell growth in the control HeLa cells. In addition, the percentages of sub-G1 and Annexin V-FITC-positive cells were augmented by Trx1 siRNA in SAHA-treated HeLa cells (Fig. 6C and D). Trx1 siRNA alone induced cell death in the control HeLa cells (Fig. 6C and D). With respect to ROS and GSH levels, treatment with Trx1 siRNA increased ROS levels including mitochondrial $\mathrm{O}_{2}^{--}$in SAHA-treated HeLa cells and in the control HeLa cells (Fig. 6E and F). GSH depletion in 
A

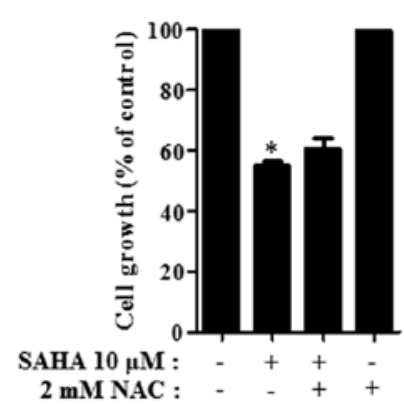

D

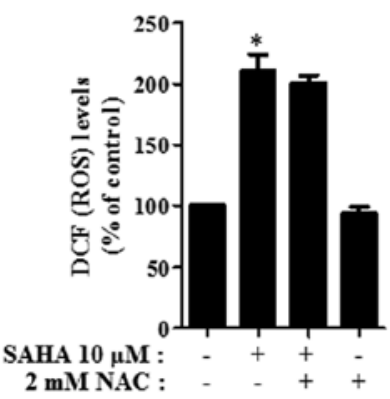

B

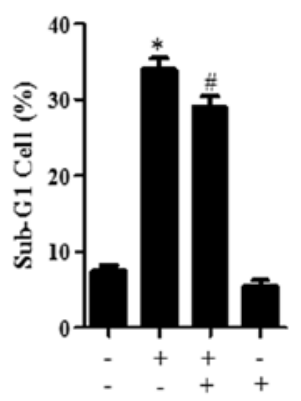

E

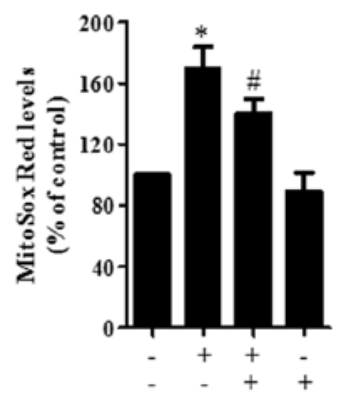

C

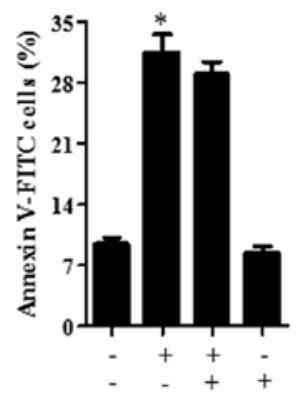

F

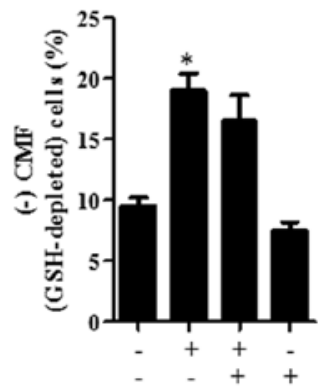

Figure 5. Effects of NAC on cell growth, cell death, ROS and GSH levels in SAHA-treated HeLa cells. Exponentially growing cells were treated with $10 \mu \mathrm{M}$ SAHA and/or $2 \mathrm{mM} \mathrm{NAC}$ for $24 \mathrm{~h}$. (A) Cellular growth changes. (B and C) The percentages of sub-G1 cells and Annexin V-positive cells, respectively. (D and E) DCF (ROS) and MitoSox (mitochondrial $\mathrm{O}_{2}^{*}$ ) levels compared with those in the control cells, respectively. (F) The percentage of (-) CMF (GSHdepleted) cells. " $\mathrm{p}<0.05$ compared with the control group. ${ }^{*} \mathrm{p}<0.05$ compared with cells treated with SAHA only.

B

A
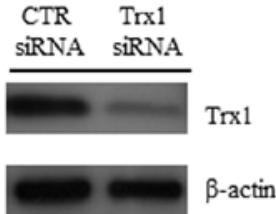

$\mathbf{E}$

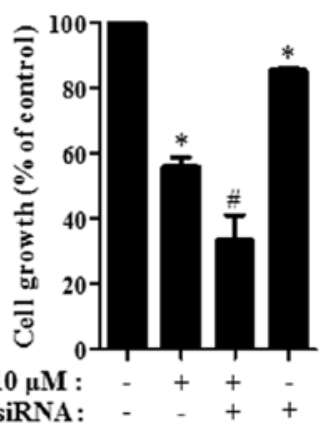

SAHA $10 \mu \mathrm{M}$ :

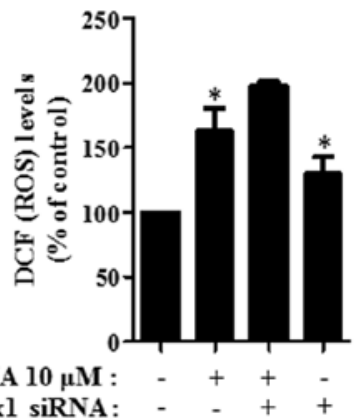

C

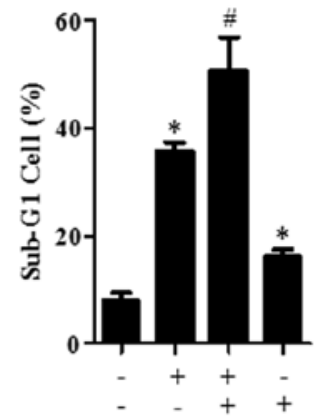

$\mathbf{F}$

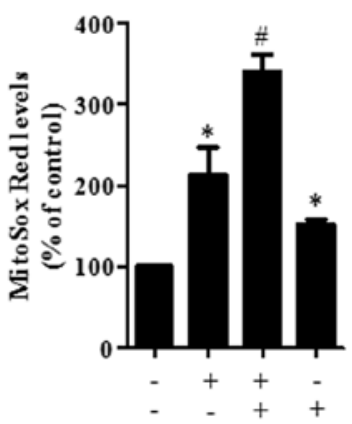

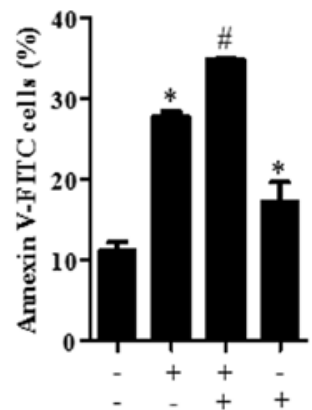

D

G

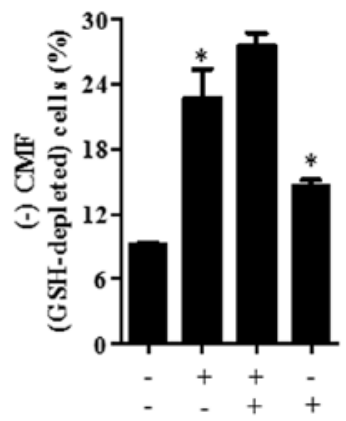

Figure 6. Effects of Trx1 siRNA on cell growth, cell death, ROS and GSH levels in SAHA-treated HeLa cells. HeLa cells $(\sim 30-40 \%$ confluence) were transfected with either CTR siRNA or Trx1 siRNA. After $24 \mathrm{~h}$, the cells were treated with $10 \mu \mathrm{M}$ SAHA for the additional $24 \mathrm{~h}$. (A) The expression of Trx1 was examined by western blotting. (B) Cellular growth changes. (C and D) The percentages of sub-G1 cells and Annexin V-positive cells, respectively. (E and F) DCF (ROS) and MitoSox (mitochondrial $\mathrm{O}_{2}^{-}$) levels compared with those in the control cells, respectively. (G) The percentage of (-) CMF (GSHdepleted) cells. ${ }^{*} \mathrm{p}<0.05$ compared with the control group. ${ }^{*} \mathrm{p}<0.05$ compared with cells treated with SAHA only. 
B

$\mathbf{A}$

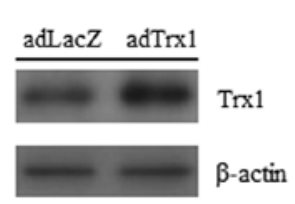

$\mathbf{E}$

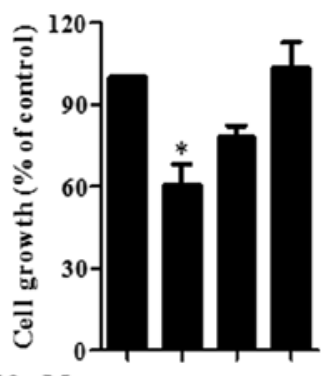

SAHA $10 \mu \mathrm{M}$ : adTrxl :

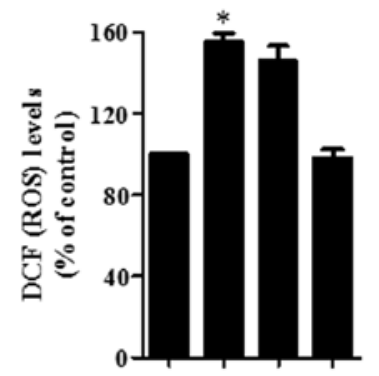

SAHA $10 \mu \mathrm{M}$ : adTrxl :
C

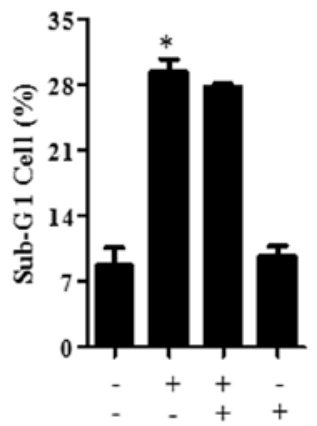

F

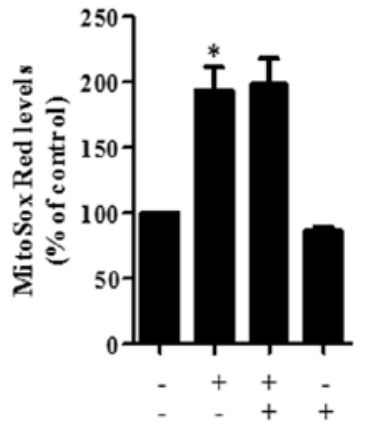

D

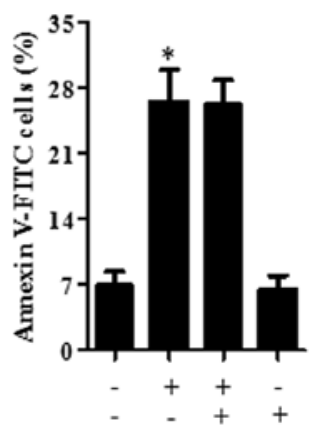

G

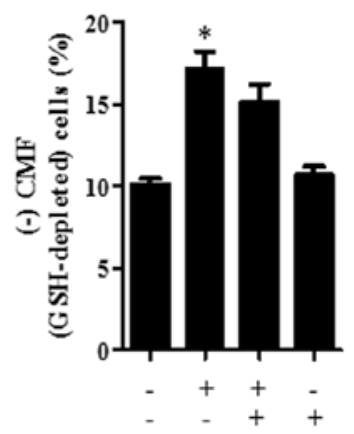

Figure 7. Effects of adTrx1 on cell growth, cell death, ROS and GSH levels in SAHA-treated HeLa cells. HeLa cells ( $\sim 50-60 \%$ confluence) were transfected with either adLacZ or adTrx1. After $24 \mathrm{~h}$, the cells were treated with $10 \mu \mathrm{M}$ SAHA for further $24 \mathrm{~h}$. (A) The expression of Trx 1 was examined by western blotting. (B) Cellular growth changes. (C and D) The percentages of sub-G1 cells and Annexin V-positive cells, respectively. (E and F) DCF (ROS) and MitoSox (mitochondrial $\mathrm{O}_{2}{ }^{*}$ ) levels compared with those in the control cells, respectively. (G) The percentage of (-) CMF (GSH-depleted) cells. " $\mathrm{p}<0.05$ compared with the control group.

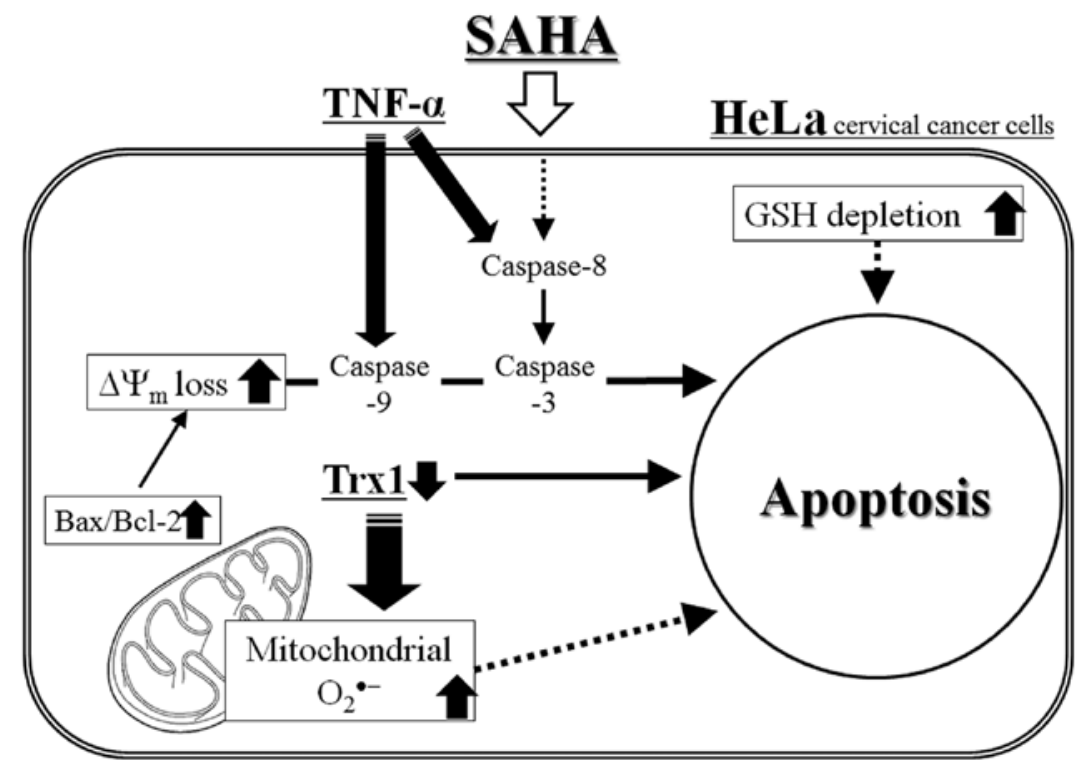

Figure 8. The proposed anticancer effects of SAHA on HeLa cervical cancer cells.

SAHA-treated HeLa cells was enhanced by Trx1 siRNA and this siRNA significantly induced GSH depletion in the control HeLa cells (Fig. 6G).
As shown in Fig. 7A, HeLa cells infected with adTrx1 showed an increase in Trx1 protein level compared with cells infected with the control adLacZ. Administration with adTrx1 
slightly attenuated cell growth inhibition and cell death in SAHA-treated HeLa cells (Fig. 7B-D). This administration seemed to decrease ROS level in the cells (Fig. 7E). However, mitochondrial $\mathrm{O}_{2}^{--}$level was not altered by adTrx1 in SAHAtreated HeLa cells (Fig. 7F). GSH depletion in SAHA-treated HeLa cells was marginally attenuated by adTrx1 (Fig. 7G).

\section{Discussion}

In the present study, we focused on assessing the effects of SAHA on HeLa cervical cancer cells in relation to cell death, ROS and GSH levels. Since SAHA increased the level of acetylated histone $\mathrm{H} 3$ in HeLa cells, SAHA appeared to act as an HDAC inhibitor in HeLa cells. SAHA decreased the growth of HeLa cells dose- and time-dependently. When the cell cycle distribution was examined, SAHA did not induce any specific phase arrest of the cell cycle in HeLa cells at $24 \mathrm{~h}$ (data not shown), instead, SAHA increased the number of sub-G1 cells and induced apoptosis, which was accompanied by the cleavage of PARP. This agent also led to loss of $\operatorname{MMP}\left(\Delta \Psi_{\mathrm{m}}\right)$ and decreased MMP $\left(\Delta \Psi_{\mathrm{m}}\right)$ levels in HeLa cells It has been suggested that a high ratio of Bax to Bcl-2 can cause the collapse of $\left(\Delta \Psi_{\mathrm{m}}\right)(37)$. Likewise, loss of apoptosis and MMP $\left(\Delta \Psi_{\mathrm{m}}\right)$ caused by SAHA were accompanied by the downregulation of Bcl-2 and upregulation of Bax. These results suggested that cell death caused by SAHA was correlated with the collapse of $\operatorname{MMP}\left(\Delta \Psi_{\mathrm{m}}\right)$ via a high ratio of Bax to $\mathrm{Bcl}-2$.

When it was determined which caspases were involved in growth inhibition and apoptosis in SAHA-treated HeLa cells, all the tested caspase inhibitors prevented SAHAinduced HeLa cell death. The activity of caspase-3 was also increased by SAHA in HeLa cells. It is reported that SAHA and TNF-family members, especially TRAIL synergistically induce apoptosis in many cancer cells such as breast, liver and lymphoma cells (34-36). According to the present data, TNF- $\alpha$ synergistically enhanced cell death in SAHA-treated HeLa cells. SAHA and/or TNF- $\alpha$ did not induce LDH release, implying that HeLa cell death caused by SAHA and/or TNF- $\alpha$ did not result from the necrotic pathway. In particular, Z-IETD and Z-LEHD significantly attenuated HeLa cell death induced by co-treatment with SAHA and TNF- $\alpha$. Therefore, the apoptotic cell death caused by SAHA and/or TNF- $\alpha$ was mediated by the extrinsic apoptotic pathway of caspase- 8 as well as the intrinsic apoptotic pathway of caspase-9.

HDAC inhibitor generates ROS in solid tumor and leukemia cells and induces apoptosis in these cells (38). Oxidative stress resulted from the increased ROS level might be involved in HDAC inhibitor-induced cell death. In fact, it is reported that NAC prevents cell death induced by HDAC inhibitors (39). Similarly, ROS levels including mitochondrial $\mathrm{O}_{2}{ }^{--}$were significantly increased in SAHA-treated HeLa cells. Caspase inhibitors showing the anti-apoptotic effects appeared to decrease ROS levels, especially mitochondrial $\mathrm{O}_{2}{ }^{\circ-}$. In particular, caspase-9 inhibitor (Z-LEHD) did not reduce ROS level derived from DCF fluorescence dye but significantly decreased mitochondrial $\mathrm{O}_{2}{ }^{-*}$ level in SAHA-treated HeLa cells. Furthermore, TNF- $\alpha$ showing an enhancement in apoptosis elevated the mitochondrial $\mathrm{O}_{2}{ }^{-}$level in SAHA-treated HeLa cells. These data suggested that changes in mitochondrial
$\mathrm{O}_{2}{ }^{--}$levels are closely related to apoptotic cell death caused by SAHA. Moreover, NAC attenuated cell growth inhibition and cell death in SAHA-treated HeLa cells and this agent significantly reduced mitochondrial $\mathrm{O}_{2}{ }^{--}$level in these cells. Taken together, SAHA-induced HeLa cell death was mediated by oxidative stress mainly derived from mitochondrial $\mathrm{O}_{2}{ }^{-}$.

Apoptotic effects are inversely proportional to $\mathrm{GSH}$ content (40-42). Similarly, SAHA increased the number of GSH-depleted HeLa cells. All the caspase inhibitors and NAC prevented GSH depletion in SAHA-treated HeLa cells. In addition, TNF- $\alpha$ marginally increased GSH depletion induced by SAHA. These results support the hypothesis that the intracellular GSH content has a decisive effect on cell death $(29,40,43)$.

SAHA alters the expression levels of many antioxidant proteins. Especially, SAHA markedly decreased Trx1 expression level. This result was similar to the report that SAHA decreased the level of Trx1 in cancer cells (19). The downregulation of Trx1 consequently seemed to influence an increase in ROS levels including mitochondrial $\mathrm{O}_{2}{ }^{--}$in SAHA-treated HeLa cells. However, the group of Holmgren reported that SAHA did not decrease Trx1 level in HeLa cells (20). Therefore, Trx1 levels could be changed depending on the incubation times and doses of SAHA. Previous studies reported that SAHA transcriptionally increases the level of TXNIP, which is an endogenous Trx1 inhibitor $(19,20)$. Likewise, SAHA increases the level of TXNIP in HeLa cells. In addition, SAHA increased the levels of Trx 2 and MnSOD. The upregulation of these antioxidants might be induced by the increased mitochondrial $\mathrm{O}_{2}{ }^{--}$level and also be transcriptionally induced by the inhibition of HDAC by SAHA. These results imply that the changes of antioxidant protein levels by SAHA affect ROS levels and they can also be regulated by ROS levels reciprocally. The transcriptional regulation of these antioxidant genes by HDAC inhibitors needs to be further studied.

The Trx antioxidant system consists of Trx, Trx R and NADPH, which is an important enzymatic network to maintain cellular redox homeostasis (8). Particularly, Trx1 is overexpressed in many cancer cells including colorectal and breast cancer and this overexpression is responsible for cellular resistance to anticancer drugs (9-11). Moreover, upregulation of $\operatorname{Trx}$ in invasive cervical carcinomas has been reported (23). Therefore, $\operatorname{Tr} x 1$ could be a new therapeutic target for cancer treatment. Other studies have reported that suppression of Trx1 can enhance cytotoxicity of anticancer drugs in human liver carcinoma and diffuse large B-cell lymphoma cells $(11,44)$. Likewise, treatment with Trx1 siRNA significantly intensified cell growth inhibition and cell death in SAHA-treated HeLa cells. Trx1 siRNA also increased mitochondrial $\mathrm{O}_{2}^{--}$level and GSH depletion in SAHA-treated HeLa cells. In contrast, the overexpression of Trx 1 marginally attenuated growth inhibition and death caused by SAHA and this overexpression also slightly reduced ROS level and GSH depletion in SAHA-treated HeLa cells. In addition, Trx 1 siRNA induced cell growth inhibition and cell death in the control HeLa cells and it increased ROS levels and GSH depletion in these cells. These results suggest that $\operatorname{Trx} 1$ has a protective role against cell death and oxidative stress in HeLa cells. 
In conclusion, as depicted in Fig. 8, SAHA induced growth inhibition and apoptosis in HeLa cervical cancer cells, which was accompanied by the intracellular increases in ROS levels and GSH depletion. TNF- $\alpha$ augmented apoptosis and ROS levels in SAHA-treated HeLa cells whereas NAC attenuated the levels in these cells. In addition, Trx 1 level was closely correlated with cell death and ROS levels in SAHA-treated HeLa cells. The present study provides important insight into the anticancer effects of SAHA on HeLa cells with respect to oxidative stress and Trx1.

\section{Acknowledgements}

This study was supported by the National Research Foundation of Korea (NRF) grant funded by the Korea government (MSIP) (no. 2008-0062279) and supported by the Basic Science Research Program through the National Research Foundation of Korea (NRF) funded by the Ministry of Education (2013006279).

\section{References}

1. Bae YS, Oh H, Rhee SG and Yoo YD: Regulation of reactive oxygen species generation in cell signaling. Mol Cells 32: 491-509, 2011

2. Bergamini CM, Gambetti S, Dondi A and Cervellati C: Oxygen, reactive oxygen species and tissue damage. Curr Pharm Des 10: 1611-1626, 2004

3. Hiraishi H, Terano A, Razandi M, Sugimoto T, Harada T and Ivey KJ: Role of cellular superoxide dismutase against reactive oxygen metabolite injury in cultured bovine aortic endothelial cells. J Biol Chem 267: 14812-14817, 1992.

4. Fiser B, Szori M, Jojart B, Izsak R, Csizmadia IG and Viskolcz B: Antioxidant potential of glutathione: a theoretical study. J Phys Chem B 115: 11269-11277, 2011.

5. Habib GM: Arsenite causes down-regulation of Akt and c-Fos, cell cycle dysfunction and apoptosis in glutathione-deficient cells. J Cell Biochem 110: 363-371, 2010.

6. Kim SJ, Jung HJ and Lim CJ: Disruption of redox homeostasis and induction of apoptosis by suppression of glutathione synthetase expression in a mammalian cell line. Free Radic Res 45: 1040-1051, 2011.

7. Collet JF and Messens J: Structure, function, and mechanism of thioredoxin proteins. Antioxid Redox Signal 13: 1205-1216, 2010.

8. Lu J and Holmgren A: Thioredoxin system in cell death progression. Antioxid Redox Signal 17: 1738-1747, 2012.

9. Noike T, Miwa S, Soeda J, Kobayashi A and Miyagawa S: Increased expression of thioredoxin-1, vascular endothelial growth factor, and redox factor-1 is associated with poor prognosis in patients with liver metastasis from colorectal cancer. Hum Pathol 39: 201-208, 2008.

10. Karlenius TC, Shah F, Di Trapani G, Clarke FM and Tonissen KF: Cycling hypoxia up-regulates thioredoxin levels in human MDA-MB-231 breast cancer cells. Biochem Biophys Res Commun 419: 350-355, 2012.

11. Li C, Thompson MA, Tamayo AT, et al: Over-expression of Thioredoxin-1 mediates growth, survival, and chemoresistance and is a druggable target in diffuse large B-cell lymphoma. Oncotarget 3: 314-326, 2012.

12. Icardi L, De Bosscher K and Tavernier J: The HAT/HDAC interplay: multilevel control of STAT signaling. Cytokine Growth Factor Rev 23: 283-291, 2012.

13. Lu Z, Luo RZ, Peng H, et al: E2F-HDAC complexes negatively regulate the tumor suppressor gene ARHI in breast cancer. Oncogene 25: 230-239, 2006.

14. Lehmann A, Denkert C, Budczies J, et al: High class I HDAC activity and expression are associated with RelA/p65 activation in pancreatic cancer in vitro and in vivo. BMC Cancer 9: 395, 2009.
15. Wang L, Zou X, Berger AD, et al: Increased expression of histone deacetylaces (HDACs) and inhibition of prostate cancer growth and invasion by HDAC inhibitor SAHA. Am J Transl Res 1: 62-71, 2009.

16. Shankar S and Srivastava RK: Histone deacetylase inhibitors: mechanisms and clinical significance in cancer: HDAC inhibitor-induced apoptosis. Adv Exp Med Biol 615: 261-298, 2008.

17. Chen MY, Liao WS, Lu Z, et al: Decitabine and suberoylanilide hydroxamic acid (SAHA) inhibit growth of ovarian cancer cell lines and xenografts while inducing expression of imprinted tumor suppressor genes, apoptosis, G2/M arrest, and autophagy. Cancer 117: 4424-4438, 2011.

18. An Z, Gluck CB, Choy ML and Kaufman LJ: Suberoylanilide hydroxamic acid limits migration and invasion of glioma cells in two and three dimensional culture. Cancer Lett 292: 215-227, 2010.

19. Butler LM, Zhou X, Xu WS, et al: The histone deacetylase inhibitor SAHA arrests cancer cell growth, up-regulates thioredoxin-binding protein-2, and down-regulates thioredoxin. Proc Natl Acad Sci USA 99: 11700-11705, 2002.

20. Ungerstedt J, Du Y, Zhang H, Nair D and Holmgren A: In vivo redox state of human thioredoxin and redox shift by the histone deacetylase inhibitor suberoylanilide hydroxamic acid (SAHA). Free Radic Biol Med 53: 2002-2007, 2012.

21. Duenas-Gonzalez A, Lizano M, Candelaria M, Cetina L, Arce C and Cervera E: Epigenetics of cervical cancer. An overview and therapeutic perspectives. Mol Cancer 4: 38, 2005.

22. Huang $\mathrm{BH}$, Laban M, Leung $\mathrm{CH}$, et al: Inhibition of histone deacetylase 2 increases apoptosis and $\mathrm{p} 21^{\mathrm{Cip} / \mathrm{WAF} 1}$ expression, independent of histone deacetylase 1. Cell Death Differ 12: 395-404, 2005.

23. Hedley D, Pintilie M, Woo J, et al: Up-regulation of the redox mediators thioredoxin and apurinic/apyrimidinic excision (APE)/Ref-1 in hypoxic microregions of invasive cervical carcinomas, mapped using multispectral, wide-field fluorescence image analysis. Am J Pathol 164: 557-565, 2004.

24. Cooper AL, Greenberg VL, Lancaster PS, van Nagell JR Jr, Zimmer SG and Modesitt SC: In vitro and in vivo histone deacetylase inhibitor therapy with suberoylanilide hydroxamic acid (SAHA) and paclitaxel in ovarian cancer. Gynecol Oncol 104: 596-601, 2007.

25. Han YH, Moon HJ, You BR, Kim SZ, Kim SH and Park WH: Effects of carbonyl cyanide p-(trifluoromethoxy) phenylhydrazone on the growth inhibition in human pulmonary adenocarcinoma Calu-6 cells. Toxicology 265: 101-107, 2009.

26. Han YH, Moon HJ, You BR and Park WH: The effect of MG132, a proteasome inhibitor on HeLa cells in relation to cell growth, reactive oxygen species and GSH. Oncol Rep 22: 215-221, 2009

27. You BR and Park WH: Proteasome inhibition by MG132 induces growth inhibition and death of human pulmonary fibroblast cells in a caspase-independent manner. Oncol Rep 25: 1705-1712, 2011.

28. You BR and Park WH: Zebularine inhibits the growth of HeLa cervical cancer cells via cell cycle arrest and caspase-dependent apoptosis. Mol Biol Rep 39: 9723-9731, 2012.

29. Han YH, Kim SH, Kim SZ and Park WH: Carbonyl cyanide p-(trifluoromethoxy) phenylhydrazone (FCCP) as an $\mathrm{O}_{2}\left({ }^{*}-\right)$ generator induces apoptosis via the depletion of intracellular GSH contents in Calu-6 cells. Lung Cancer 63: 201-209, 2009.

30. Han YH and Park WH: Propyl gallate inhibits the growth of HeLa cells via regulating intracellular GSH level. Food Chem Toxicol 47: 2531-2538, 2009.

31. Elbashir SM, Harborth J, Lendeckel W, Yalcin A, Weber $\mathrm{K}$ and Tuschl T: Duplexes of 21-nucleotide RNAs mediate RNA interference in cultured mammalian cells. Nature 411: 494-498, 2001.

32. You BR and Park WH: Arsenic trioxide induces human pulmonary fibroblast cell death via increasing ROS levels and GSH depletion. Oncol Rep 28: 749-757, 2012.

33. You BR and Park WH: Suberoyl bishydroxamic acid-induced apoptosis in HeLa cells via ROS-independent, GSH-dependent manner. Mol Biol Rep 40: 3807-3816, 2013.

34. Lauricella M, Ciraolo A, Carlisi D, Vento R and Tesoriere G: SAHA/TRAIL combination induces detachment and anoikis of MDA-MB231 and MCF-7 breast cancer cells. Biochimie 94: 287-299, 2012. 
35. Carlisi D, Lauricella M, D'Anneo A, et al: The histone deacetylase inhibitor suberoylanilide hydroxamic acid sensitises human hepatocellular carcinoma cells to TRAILinduced apoptosis by TRAIL-DISC activation. Eur J Cancer 45: 2425-2438, 2009.

36. Al-Yacoub N, Fecker LF, Mobs M, et al: Apoptosis induction by SAHA in cutaneous T-cell lymphoma cells is related to downregulation of c-FLIP and enhanced TRAIL signaling. J Invest Dermatol 132: 2263-2274, 2012.

37. Martinou JC and Youle RJ: Mitochondria in apoptosis: Bcl-2 family members and mitochondrial dynamics. Dev Cell 21: 92-101, 2011

38. Eot-Houllier G, Fulcrand G, Magnaghi-Jaulin L and Jaulin C: Histone deacetylase inhibitors and genomic instability. Cancer Lett 274: 169-176, 2009.

39. Ungerstedt JS, Sowa Y, Xu WS, et al: Role of thioredoxin in the response of normal and transformed cells to histone deacetylase inhibitors. Proc Natl Acad Sci USA 102: 673-678, 2005.
40. Han YH, Kim SZ, Kim SH and Park WH: Intracellular GSH level is a factor in As4.1 juxtaglomerular cell death by arsenic trioxide. J Cell Biochem 104: 995-1009, 2008.

41. Han YH, Kim SZ, Kim SH and Park WH: Enhancement of arsenic trioxide-induced apoptosis in HeLa cells by diethyldithiocarbamate or buthionine sulfoximine. Int J Oncol 33: 205-213, 2008

42. Han YH, Kim SZ, Kim SH and Park WH: Suppression of arsenic trioxide-induced apoptosis in $\mathrm{HeLa}$ cells by $\mathrm{N}$-acetylcysteine. Mol Cells 26: 18-25, 2008.

43. Estrela JM, Ortega A and Obrador E: Glutathione in cancer biology and therapy. Crit Rev Clin Lab Sci 43: 143-181, 2006

44. Tian C, Gao P, Zheng Y, et al: Redox status of thioredoxin-1 (TRX1) determines the sensitivity of human liver carcinoma cells $(\mathrm{HepG})$ to arsenic trioxide-induced cell death. Cell Res 18: 458-471, 2008. 